\section{VARIATION IN THE PLATELET COUNT}

ITS CAUSE AND CLINICAL SIGNIFICANCE *

W. W. DUKE, M.D.

Professor of Experimental Medicine, University of Kansas, School of Medicine

KANSAS CITY, MO.

Remarkably little interest is taken in blood platelets by clinicians, so little in fact that I really hesitate to present a paper on this subject before the section. There are scarcely more than ten or twelve investigators working in this field at the present time, I believe. Nevertheless, platelets are very interesting and remarkable little bodies, and if time permitted me to enumerate some of the interesting facts and problems concerning them, I feel sure you would be convinced that they are worthy of more attention than they receive. This paper must be confined, however, to a brief report of clinical and experimental observations which are thought to throw new light on some of the factors which influence the number of platelets in the circulating blood. They should aid one, therefore, in drawing conclusions from the platelet count in clinical cases.

The platelet count is altered in a great number of diseases. ${ }^{1}$ The alterations noted by different observers have been uniform in but few diseases; in fact, there are few lines of investigation in which opinions have been so divergent. One fact on which there is general agreement is that the count is reduced during the febrile period of acute infectious disorders, and increased during convalescence. This interesting change in the count was first observed by Hayem, and was referred to as a hematoblastic crisis. Hayem considered it an effort at blood regeneration. There are striking exceptions to the foregoing generalization. In Escherich's clinic I made a series of platelet counts in diphtheria-a good example of an acute infectious disease. The count was usually reduced during the febrile period of the affection (lowest count 3,000 ), and increased during convalescence (highest count 750,000 ). Occasionally, however, the findings were diametrically opposite to this; that is, the count was normal or increased during the febrile period (highest count 750,000$)$, and normal or reduced during convalescence (lowest count 135,000 ).

In many chronic diseases the majority of observers have noted an increased count, and some have considered this a general rule. In Romberg's clinic I made a series of counts in tuberculosis--a good example of a chronic infectious disease. In harmony with the results of other writers, the count was usually increased, occasionally very much increased (highest count over 1,000,000). In two instances, however, it was very much reduced for several days (in one case to 55,000 , in another to less than 1,000). Likewise in a series of observations made in nephritis, the count was often increased when an acute process was demonstrable or when there was marked evi-

* From the University of Kansas, School of Medicine, Rosedale, Kan. ${ }^{*}$ Read before the Section on Practice of Medicine at the Sixty-
Sixth Annual Session of the American Medical Association, San Fran-

Sixth Annual Session
cisco, June, 1915 .

1. Determann: Klinische Untersuchungen über Blutplattchen, Arch. f. klin. Med., 1898, p. 365. Helber, E.: Ueber die Zahlung der Blutplattchen Im Blute des Menschen und ihr Verhalten bei pathologischen Zustanden, Deutsch. Arch. f. klin. Med,, 1904, xxi, 316. Kemp, G. T.; Calboun, Henrietta, and Harris, C. E.: The Blood Plates: Their Enumer. ation in Physiology and Pathology, THE Journal A. M. A., April 7, 1906, p. 1022; April 14, 1906, p. 1091. Wright, J. H., and Kinnicutt, Roger: A New Method of Counting the Blood Platelets for Clinical Purposes, THE Journat A. M. A., May 20. 1911, p. 1457. dence of renal insufficiency. Occasionally the count was very much increased (highest count $1,260,000$ ). In one case, however, it was very much reduced (lowest count below 10,000).

One interesting feature has characterized the counts which I have made both in man and in animals. When the individual was normal and remained in a given environment, the count remained relatively constant. When the count was markedly increased or markedly reduced by pathologic conditions, it had a tendency to fluctuate. In Chart 1 is shown graphically the platelet count of four normal individuals in the same environment. During a period of eleven days, there was relatively little variation. It fell constantly between the limits of 200,000 and 400,000 . In marked contrast to this is the extreme variability of the pathologic counts shown in Chart 2. In one, a case of advanced tuberculosis, the count varied from less than 1,000 to 720,000 . In the other, a case of nephritis, the count varied from 350,000 to $1,400,000$.

It is believed that the experiments to be reported subsequently throw light on the cause of these apparently errotic results.

\section{EFFECT OF DIPHTHERIA TOXIN ON THE PLATELET COUNT ${ }^{2}$}

Diphtheria toxin offered a most promising means of studying pathologic variation in the platelet count. In the first place, the platelet count is highly variable in diphtheria; in the second place, we might reasonably suppose that th:s variability is a direct result of the action of diphtheria toxin. For this reason, diphtheria toxin was introduced into rabbits in doses of different sizes and its effect on the platelet count noted. ${ }^{3}$

In Chart 3 are recorded the platelet counts of three rabbits following the injection of a dose of diphtheria toxin which caused death in from three to four days. In each case there was a rapid fall in the ccunt. Necropsy showed degeneration of the marrow in high degree. The nuclei of a majority of the megakaryocytes were vacuolated or pyknotic.

In contrast to the foregoing are the results recorded in Chart 4. Here is shown the effect of sublethal doses of diphtheria toxin in three rabbits. The amount of toxin given: in these experiments made the animals appear ill for several days. All recovered, however, and were lively throughout the remainder of the experiment. There was first notice a marked rise in the platelet count. In one instance the count reached a height of $2,000,000$. There was next noted a rapid fall in the count. In one instance the count reached the low level of 4,000 . This was followed by a second rise in the count, which in one instance reached a height of 2,000,000.

Deduction.-Diphtheria toxin in large doses causes an immediate fall in the platelet count. This is presumably the result of a poisonous action of diphtheria toxin on the bone marrow. In sublethal doses it causes first a rise and later a fall in the count. The latter effect may be followed by a secondary rise in the count. In some cases the count does not descend below normal, so that the only effect actually observed is an increased count. These changes are believed to be due to an irritant effect of small doses of diphtheria toxin on the marrow or an irritant followed by a poisonous effect.

2. The platelet counts in these experiments have been reported in detail in a previous paper (Duke, W. W.: Causes of Variation in the detail in a previous paper (Duke, W. W.: Causes of Varian, 1913, p. 100).
Platelet Count, Arch. Int. Med., January,

3. Blood platelets in rabbits are more difficult to count than those 3. Blood platelets in rabbits are more difficult to count than those
in man. They are smaller and more variable in size and shape, ang unless the ingredients of Wright's solution are balanced with care, the platelets will either clump or go into solution. The precautions neces. sary to obtain reliable counts have been mentioned in a previous paper (Duke, W. W.: Rate of Regeneration of Blood Platelets, Jour. Exper. Med., 1911, xiv, 265). 


\section{THE EFFECT OF TETANUS TOXIN ON THE} PLATELET COUNT

Because of the interesting results obtained with diphtheria toxin, tetanus toxin was tried. The counts recorded in Chart 5 were observed in three animals which received subcutaneously a large dose of a recently prepared solution of tetanus toxin (eight. times the minimum lethal dose for a guinea-pig weighing 250 grams). Although this amount of toxin caused the death of one animal, and marked toxic symptoms in the other two, there was little change in either the platelet or white count. It hardly seemed worth while to pursue this line of work further.

Deduction.-These experiments are hardly complete enough to justify a sweeping conclusion concerning the action of tetanus toxin. At any rate, it may be said that its effect on the platelet count is not nearly so great as that of diphtheria toxin.

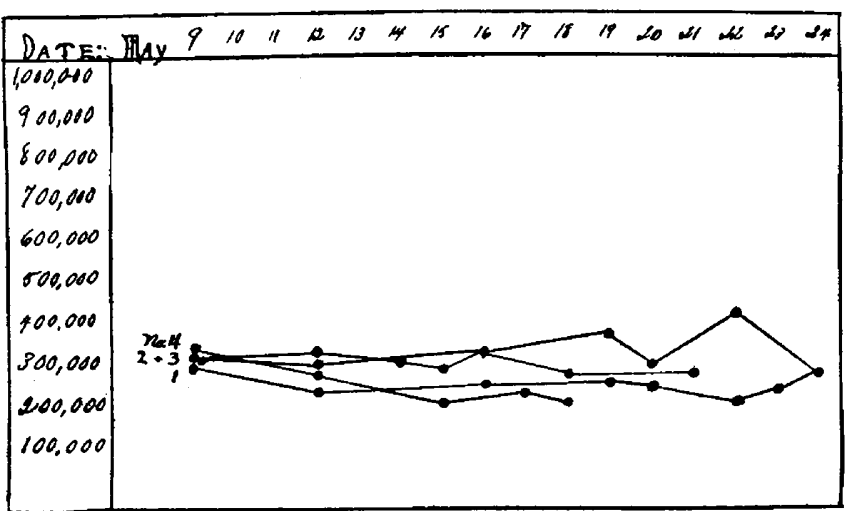

Chart 1.-Platelet count of four normal individuals in the same environment. Note the relatively slight variation of the counts during a period of eleven days. injection, but were lively and well throughout the remainder of the experiment. There was in each instance a definite rise in the platelet count which persisted for a few days. In one instance the count reached a height of $1,375,000$.

In Chart 7 are recorded results showing the effect of 4.5 c.c. of the same suspension given intravenously instead of subcutaneously. The dose in this case was 3,000 million. Two of the animals were found dead the day following the injection. The one that lived appeared very ill for three days, but was lively and well throughout the remainder of the experiment. There was a marked fall in the platelet count (from 1,210,000 to 340,000 ) which persisted for a few days. This line of investigation did not promise to yield results of great interest and was discontinued.

Deduction.-The effect of killed typhoid bacilli on the platelet count is marked but not extreme or prolonged. Large doses given subcutaneously increase the count. Large doses given intravenously decreased the count for a few days in the one animal which survived this

THE EFFECT OF KILLED TYPHOID BACILLI ON THE PLATELET COUNT ${ }^{4}$

Killed typhoid bacilli were chosen for study because of the marked changes in the platelet count which occur in typhoid fever. It was hoped that some of the poisons which produce these changes might be present in the dead bacilli. Killed cultures were employed instead of living bacteria in order that the dose given could be definitely known and not modified by multiplication of bacteria in the animal. The resulting changes in the platelet count were definite treatment. One might judge that large intravenous doses poison, and smaller subcutaneous doses stimulate the production of platelets.

THE EFFECT OF BENZOL ON THE PLATELET COUNT ${ }^{3}$

The effect of benzol (benzene, $\mathrm{C}_{6} \mathrm{H}_{8}$ ) on the platelet count was studied in both dogs and rabbits. L. Selling ${ }^{5}$ had previously shown that benzol poisoning causes a reduction in the leukocytes in man and rabbits and concluded that this wa; a result of the degenerative changes he found in the bone marrow. It seemed that benzol might have an interesting effect on the platelet count also.

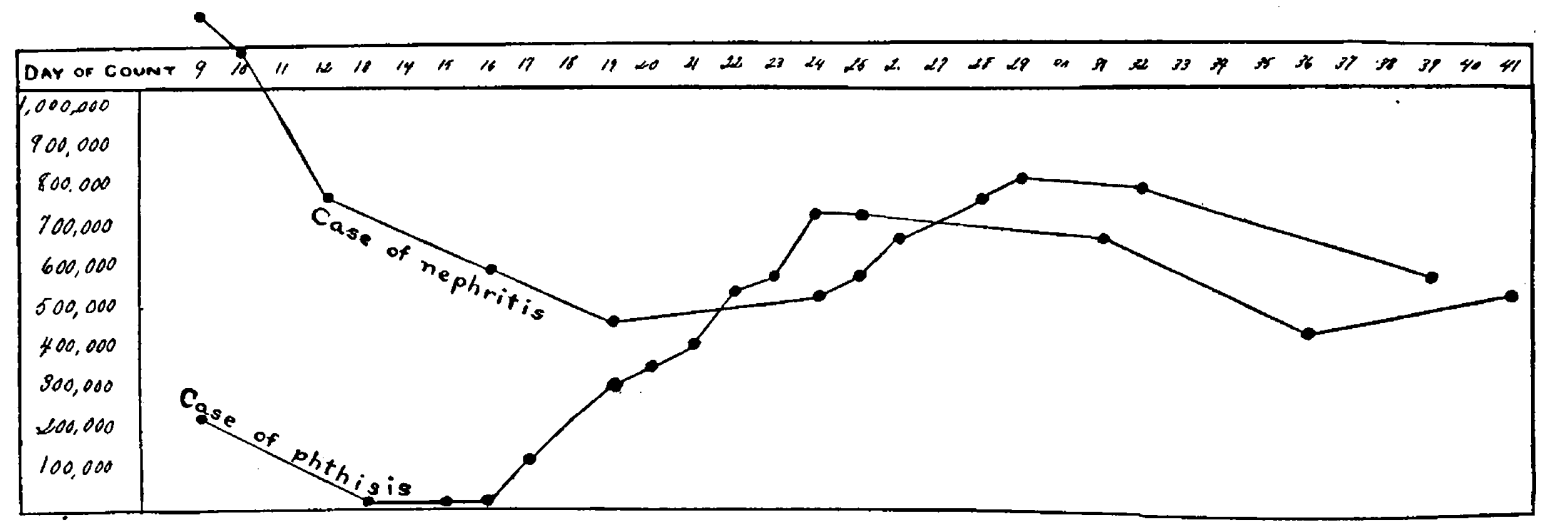

Clart 2.-Platelet counts in a case of tuberculosis and in a case of nephritis. These illustrate the variability of pathologic counts.

and marked, but not so great as those which followed the use of diphtheria toxin.

In Chart 6 are recorded the platelet counts of three rabbits which received subcutaneously 1,000 million dead typhoid bacilli, suspended in 1.5 c.c. of salt solution. The culture used had been obtained from a case of typhoid fever several months previously. The bacilli were obtained from a fortyeight-hour growth on agar-agar, were suspended in salt solution, and killed by heat $(58 \mathrm{C}$. [136.4 F.] for one-half hour). The animals appeared ill for three days following the

4. These experiments are of little interest except as recounted here, and hardly justify a more detailed report.
Twelve dogs were given subcutaneously several doses of from 2 to 40 c.c. of Merck's benzol. They all showed profound symptoms of poisoning and died in from four days to three weeks after the first injection. The platelet count fell rapidly in almost every instance. Little if any initial rise was noted. Typical experiments are summarized in Tables 1-4.

Necropsy showed in each instance a hyperemic degenerated bone marrow. The nuclei of most of the megakaryocytes were vacuolated or pyknotic.

Rabbits are not so severely poisoned by benzol as dogs, and are better adapted to this study. In Chart 8 are recorded

5. Selling, L.: Benzol als Leukotoxin, Beitr. z. path. Anat. u. z. allg. Path., 1911, li, 576. 
results showing the effect on the platelet count of five 2 c.c. doses of benzol, given at intervals of twenty-four hours. There was first a marked rise in the count, which in one instance reached a height of

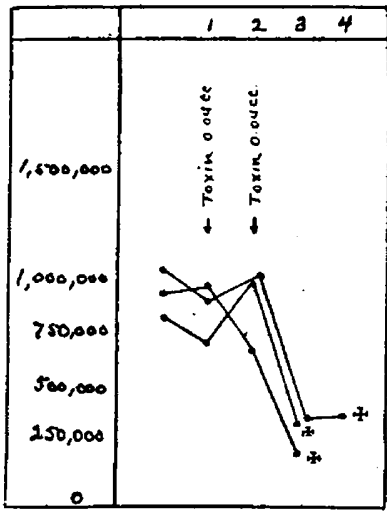

Chart 3.--Effect of diphtheria toxin on the platelet count of three rabbits in doses which four days. caused death in from three to $1,230,000$. This was followed by a rapid fall in the count, which in one instance reached the low level of 56,000. One rabbit died and the other was killed. The bone marrow was degenerated in high degree. Few megakaryocytes were to be found.

Chart 9 shows the effect of three 2 c.c. doses of benzol. This caused simply a rise in the count, which in one instance reached a height of $1,780,000$. These rabbits showed no visible ill effects from the benzol. They remained lively and apparently well throughout the experiment.

Deduction. - B e $\mathrm{n} z$ o 1 given subcutaneously in large doses to dogs causes an immediate fall in the platelet count. In smaller doses it causes a lowering of marked fall in the platelet count. There was also a marked fall in the leukocyte count.

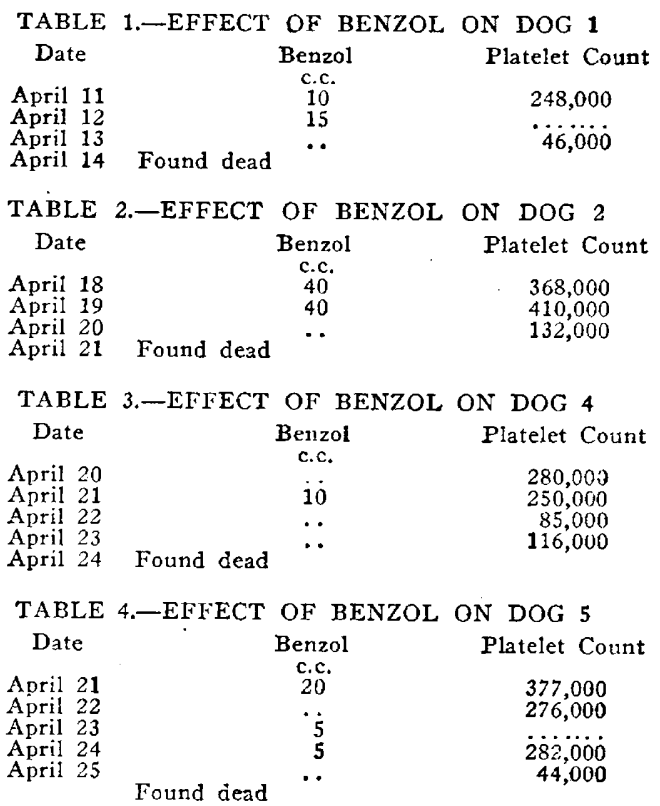

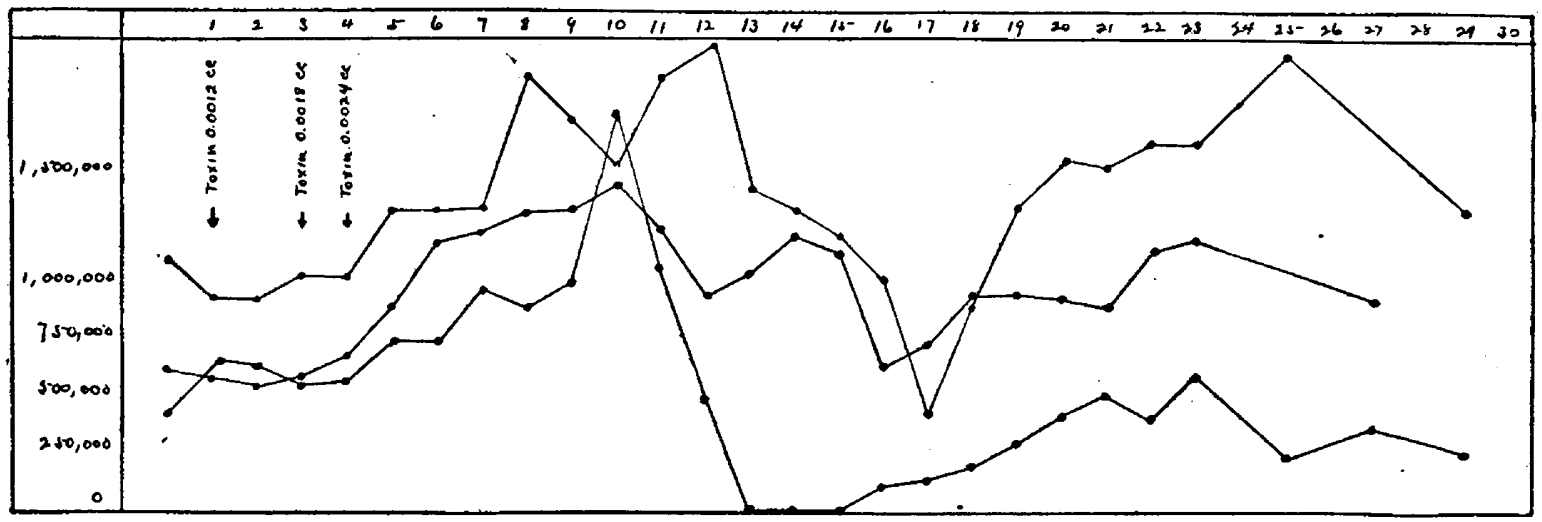

Chart 4.-Effect of sublethal doses of diphtheria toxin on the platelet count of three rabbits.

the count, but the effect is not so rapid. This effect is believed to be a result of a toxic action of benzol on the bone marrow. Benzol given in large doses to rabbits causes first a rise and later a fall in the count. In smaller doses it causes a rise only. This is believed to be an irritant effect of benzol on the marrow or an irritant followed by a toxic effect.

\section{THE EFFECT OF THE ROENTGEN RAY ON THE PLATELET COUNT ${ }^{6}$}

Heineke found that intensive doses of the Roentgen ray cause a reduction in the leukocyte count and destruction of the parenchymatous elements of the marrow. It seemed possible that this agent might also have an effect on the platelet count.

Chart 10 shows the effect of an intensive dose of the Roentgen ray on the platelet count of three rabbits. (Exposure made at 13 inch anode distance with Coolidge tube, $2 \mathrm{~mm}$. aluminum filter, 7 inch spark gap, one-half erythema dose with Hampson's pastille. Exposure repeated in two days with three-fourths erythema dose at skin.)

These were typical experiments. A similar result was obtained in six other cases. In every instance there was a

6. These experiments were carried out in collaboration with Dr. E. H. Skinner, and will be reported in detail subsequently.

7. Heineke: Untersuchung über der Einwirkung der Röntgenstrahlungen auf der Knockenmark, nebst einigen Bemerkungen über die Röntgentherapie der Leukämie und Pseudoleukämie und des Sarkoms, Deutsch. Zischr. f. Chir., 1905, lxxviii, 196.
Chart 11 shows the effect of a shorter exposure (one-fourth erythema dose at skin through $1 \mathrm{~mm}$. aluminum filter). In each instance a rise eventually followed. One of the three

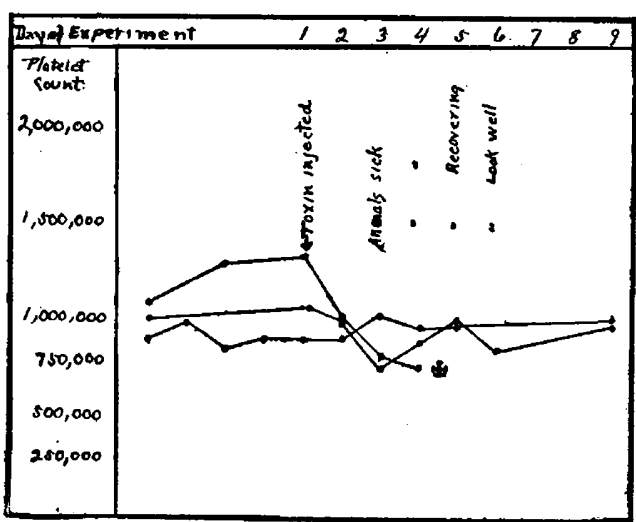

Chart 5.- Effect of large doses of tetanus toxin on the platelet count in three rabbits.

rabbits had a very high count to begin with. In this case a rapid fall preceded the rise. A second dose of the same intensity caused in these rabbits a rapid fall in the count. In these experiments a leukopenia also appeared. 
Deduction. - The Roentgen ray in massive dose causes a fall in the platelet count. In smaller doses it causes a rise in the count.

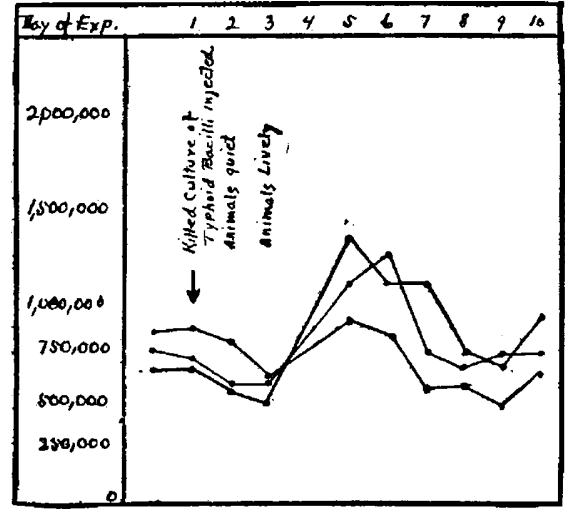

Chart 6.-Effect on the platelet count of 1,000 million killed typhoid bacilli given subcutaneously to cach of three rabbits.

Heineke's experiments showing that the Roentgen ray in large doses is followed by degeneration of the marrow suggest that the foregoing results are the effect, respectively, of toxic and stimulating doses of the Roentgen ray on the bone marrow.

\section{THE EFFECT OF TUBERCULIN ON THE PLATELET COUNT}

Tuberculin was given subcutaneously or intravenously, in doses varying from 0.1 to 5 c.c. in eighteen experiments. It was hoped that some of the interesting changes in the platelet count observed in tuberculosis might be reproduced. Tuberculin caused a slight change in the platelet count in every instance. When injected subcutaneously it caused a rise in the count which persisted for a number of days. The effect, as a rule, was not great or prolonged, unless some complication, such as anemia or ulceration of the

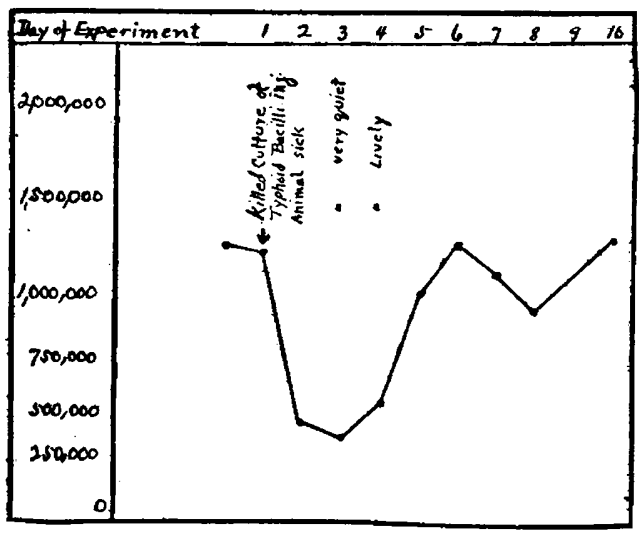

Chart 7.-Effect on the platelet count of 3,000 million killed typhoid bacilli given intravenously to one rabbit. skin, developed. It seemed impos.

sible to give subcutaneously a dose great enough to cause a fall in the count. This was accomplished in all of the six experiments in which tuberculin was given intravenously, but the lowering of the count was transitory (two days) and was quickly followed by a rise. Second doses, given from six to eight weeks after the first, caused a similar change. In Charts 12 and 13 are recorded six typical experiments.

Deduction.-The effect of tuberculin on the platelet count is similar to that which follows the use of typhoid bacilli. It is marked but not great. Large doses given subcutaneously invariably cause a rise in the count. Large doses given intravenously cause a fall in the count which is quickly followed by a return to normal or a rise.

\section{GENERAL SUMMARY AND THEORETICAL CONSIDERATIONS}

The experiments reported here are believed to have disclosed several facts which can be applied to explain the behavior of the platelet count in certain types of diseases. First of all, it may be stated that it was possible to reduce the platelet count by using a large dose of any agent which in smaller dose caused a rise in the count and vice versa. The agents used were varied in character, namely, toxins, bacterial emulsions, a chemical poison and the Roentgen ray. Some of the agents used had a rapid and profound effect on the count (diphtheria toxin and benzol). Others had a smaller effect (the Roentgen ray, typhoid bacilli and tuberculin). One of them (tetanus toxin) had almost no effect, although the dose used killed one of three animals and caused toxic symptoms in the others. The agents with which it was possible to produce the most rapid and extreme rises in the count, namely, diphtheria toxin and benzol, were also the ones with which the most rapid and extreme falls in the count were produced.

These facts are in harmony, I believe, with the numerous well-known biologic observations concerning stimulants or irritants which act as poisons if employed in sufficient dosage. The most powerful stimulants are also the most powerful poisons, as a rule.

The foregoing generalizations may be employed in the following way to explain the changes in the platelet count in disease. It is believed that diseases in which the platelet count is effected directly by circulating poisons may be divided into two classes.

In the first class come diseases in which powerful irritants to the platelet-forming organs (such as diphtheria toxin and benzol) are elaborated. It is believed that, in diseases of this sort, both high and low counts frequently occur, and also rapid changes from high counts to low counts and vice versa. Some change in the count might be expected even in the mildest cases. That is, when the toxin has such a profound influence on the count, we should expect that a sufficient quantity would be formed in nearly every case, to have its irritant effect, at least. We should also expect that the irritant dose would be exceeded frequently so that the lowered counts would be found as often, or perhaps more often, in the average run of cases, than high counts. The first phase of

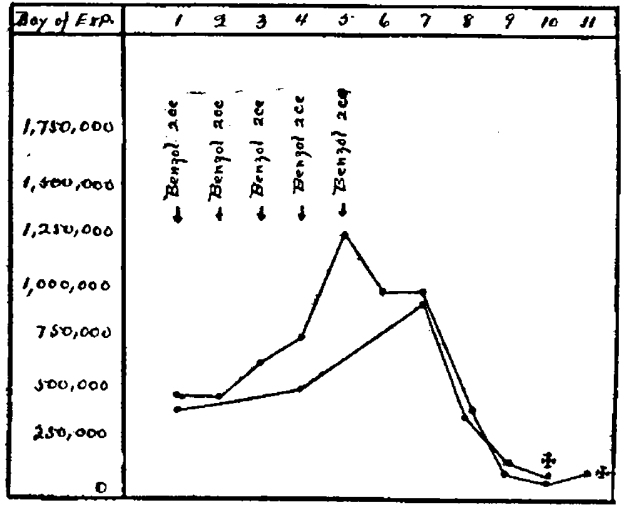

Chart 8.-Effect of five 2 c.c. doses of benzol in two rabbits.

Hayem's hematoblastic crisis (the fall during the febrile period of an acute disease), according to this view, would be the effect of a quantity of toxin which acted as a poison to the platelet-forming organs. The second 
phase (the rise during convalescence) would be a secondary rise after neutralization of the poison. This type of change is the rule in diphtheria-an excellent example of an acute infectious disease. The opposite type of change observed in diphtheria, that is, a rise during the febrile period followed by a fall during convalescence, is believed to occur when the toxemia is less intense. A hematoblastic crisis would be the
One might believe, and perhaps with reason, that there exist toxins which can have only a poisonous effect on the marrow, and can never increase the count. The existence of such, however, is not proved by these experiments.

There exist, without question, toxins which have very little if. any influence on the count. Tetanus toxin is perhaps an example of this type.

Factors other than those noted above also modify the platelet count. It is difficult to say whether or not they may have played a rôle in some of the cases and experiments here reported. The very interesting observation has been made by Hayem, Gley and others, ${ }^{8}$ that, following the injection of peptone, in dogs, the platelets tend to clump and can be found forming capillary plugs in the lungs, liver and other organs. Von Behring and others observed the same phenomenon during anaphylactic shock. I endeavored to find the degree to which the platelet count could be lowered in dogs by an intravenous injection of peptone. The count was lowered without question, but accurate

Chart 9.-Effect of three 2 c.c. doses of benzol on the platelet count in rabbits. counts were impossible on account of
of the platelets. Masses of 100 or more

rule, then, in all acute diseases in which toxins or irritants are produced in the average case in quantity sufficient to act as a poison to the platelet-forming organs.

Chart 14, in which is shown graphically the effect of varying doses of diphtheria toxin on the platelet count in rabbits, illustrates graphically experiments which seem to be a substantial basis for these statements, and shows the extent to which the platelet count may vary in different grades of the same pathologic condition.

In the second class come diseases in which the irritants produced are mild. One might infer that the counts would here follow the same general law, but that the relative frequency of increased and decreased counts would be different. Increased counts in this case would be the rule. Perhaps a mild irritant, the effects of which could continue as an irritant for a p rolong ed period, would give rise to a greater increase in the count than the more powerful ones, the poisonous effects of which would appear more quickly. Low counts, the effect of an overwhelming dose, could occur, but would be less frequently observed than in the case of a stronger agent. Tuberculosis and nephritis would appear to be good examples of such a disease. Here the count is almost always increased, but is in rare instances reduced. The experiments with killed typhoid bacilli and tuberculin are thought to be imitations of this type of disease. It was easy to increase the count with these agents. A reduced count was brought about only by giving very large doses intravenously. clumping of the platelets. Masses of 100 or more
were observed. The day following the injection, the

TABLE 5.-EFFECT ON THE PLATELET COUNT OF A DOSE OF HORSE SERUM GIVEN TO SENSITIZED RABBITS

\begin{tabular}{|c|c|c|}
\hline & Rabbit A & Rabbit B \\
\hline 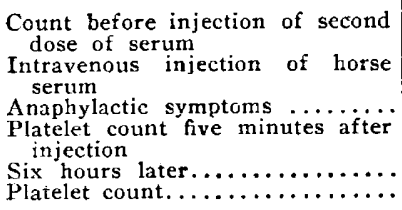 & $\begin{array}{l}1,320,000 \\
0.5 \text { c.c. } \\
\text { Very slight } \\
2,120,000 \\
\text { Animal well } \\
2,040,000\end{array}$ & $\begin{array}{c}1,610,000 \\
0.5 \text { c.c. } \\
\text { Marked } \\
490,000 \\
\text { Complete recovery } \\
1,060,000\end{array}$ \\
\hline
\end{tabular}

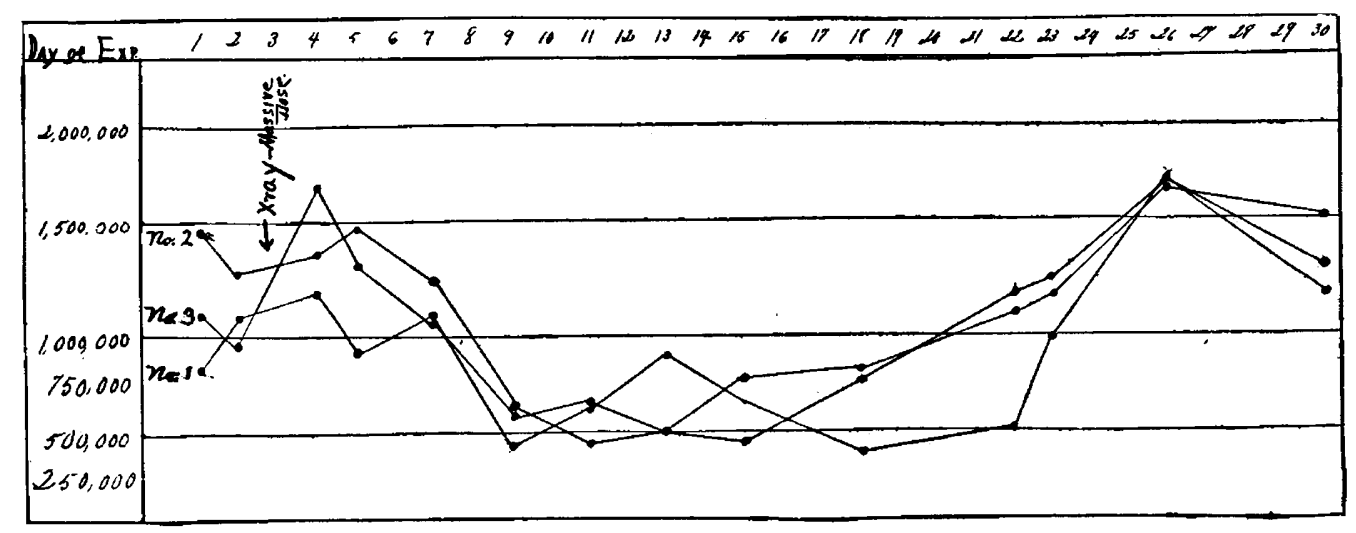

Chart 10.-Effect of an intensive dose of the Roentgen ray on the platelet count of three rabbits. count had returned to normal-in fact, it became greater than normal. The tendency to clumping was no longer noticeable.

The experiments given in Table 5 show the change in the platelet count in two rabbits which received 0.5 c.c. of horse serum. Each had been sensitized by an injection of horse serum, nine weeks previously. Rabbit B displayed marked symptoms of anaphylactic shock. The platelet count in this animal was reduced

8. Gley: Compt. rend. Soc. de biol, 1896, iv, 44. Von Behring: Deutsch. med. Wchnschr., Oct. 15, 1914, xl, No. 42 . 
for a short time, and a slight tendency to clumping was observed. Rabbit A displayed little or no evidence of shock. The platelet count was actually increased. No clumping was observed.

The experiments given in Table 6 are reported for comparison with the preceding. In these experiments, varying doses of horse serum were given intravenously to unsensitized rabbits. The changes are small.
The agents employed were varied in nature, namely, diphtheria toxin, benzol, the Roentgen ray, killed typhoid bacilli and tuberculin. Tetanus toxin, in the dose used, had very little effect on the count. It is reasonable to conclude, I think, that the foregoing agents in the smaller doses acted as irritants to the platelet-forming organs, and in this way caused a rise in the platelet count. In larger doses they acted as poisons, or first as irritants and then as poisons, and caused thereby a fall in the count, or a rise followed by a fall.

The experimental data harmonize with observations on the platelet count in the clinical conditions thus far studied. For example, in a large number of counts made by the writer in diphtheria, tuberculosis and nephritis, both increased and reduced counts were observed. A review of the literature shows that in most diseases in which the platelet count is profoundly altered, both increased and reduced counts have been observed. In the light of the foregoing experiments, these clinical Chart

Other factors also modify the platelet count. Richardson ${ }^{9}$ and others state that it is increased after hemorrhage. Kemp, Calhoun and Harris, ${ }^{1}$ and $\mathrm{Webb}^{10}$ find that it is increased by altitude: Rebaudi ${ }^{11}$ reports a marked increase during pregnancy. Kemp, Calhoun and Harris state that it is higher in cold seasons than in warm seasons.

To conclude, it may be stated that evidently several factors play a part in modifying the platelet count in disease. This fact, however, does not conflict with a conclusion that, in many diseases, substances are formed which may act as either irritants or poisons to the platelet-forming organs, and, depending on the intensity of their action, may exert their influence either to increase the count or reduce it. If this conclusion is substantial, the apparently contradictory reports in the literature on platelet counts seem in reality harmonious.

\section{CONCLUSIONS}

It is believed that the experiments here reported may be employed to explain the behavior of the platelet count under pathologic conditions. Primarily, it may be stated that every agent with which the animals were treated, which exerted any marked influence on the platelet count, increased the count when small doses were used and reduced it when larger doses were given.

9. Richardson, F. L.: The Effect of Severe Hemorrhage on the Number of Blood Platelets in Blood from the Peripheral Circulation of Rabbits. Jour. Med. Research, 1904, viii, 99

10. Webb, Gilbert and Havens: Blood Platelets: Some Studies in Con nection with Altitude and Tuberculosis, Preliminary Report, Colorado Medion wour., 1914.

11. Rebaudi: Blood Platelets During Pregnancy, Labor, Puerperium and Menstruation and in the New Born, Am. Jour. Obst., 1907, p. 475. observations would not appear contradictory. It is believed that in almost every disease in which the numtoxins or poisons, the count may be either increased

TABLE 6.-EFFECT OF VARYING DOSES OF HORSE SERUM ON THE PLATELET COUNT IN RABBITS

\begin{tabular}{|c|c|c|c|}
\hline & Rabbit 1 & Rabbit 2 & Rabbit 3 \\
\hline $\begin{array}{l}\text { Normal count } \ldots \ldots \ldots \ldots \\
\text { Herse serum } \ldots \ldots \ldots \ldots . \\
\text { One hour after injection. } \\
\text { Twenty-four hours after } \\
\text { injection }\end{array}$ & $\begin{array}{l}2,000,000 \\
0.001 \\
1,910,000 \\
2,380,000\end{array}$ & $\begin{array}{l}1,450,000 \\
1 \text { c.c. } \\
1,780,000 \\
2,220,000\end{array}$ & $\begin{array}{l}1,450,000 \\
5 \text { c.c. } \\
1,270,000 \\
1,660,000\end{array}$ \\
\hline
\end{tabular}
ber of platelets is markedly influenced by circulating

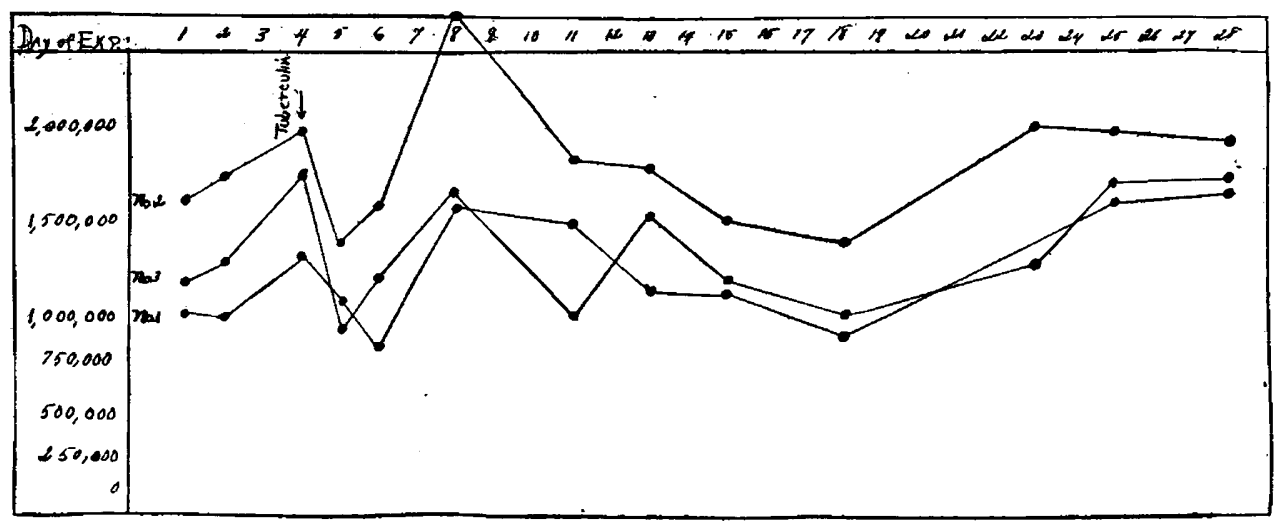

Chart 12.--Effect on the platelet count of 3 c.c. of Koch's old tuberculin given intravenously to three rabbits.

or reduced according to the intensity and duration of their toxic action on the bone marrow. It must be added here that, as has been mentioned in the text, the platelet count may be influenced also by other factors, such as altitude, hemorrhage, peptone poisoning, anaphylaxis, and also by some of the so-called diseases of the bone marrow.

One other important generalization is possibly justified. In certain chronic diseases, tuberculosis and nephritis for example, the count is increased as a 
rule and reduced in rare instances only. In other diseases, diphtheria, pneumonia, and typhoid fever, for example, the findings are diametrically opposite; that is, the count is reduced as a rule and increased in rare instances. It is believed that in the former type of diseases (increased counts the rule), the platelet count is influenced by some mild irritant to the platelet-forming organs, such as killed typhoid bacilli or

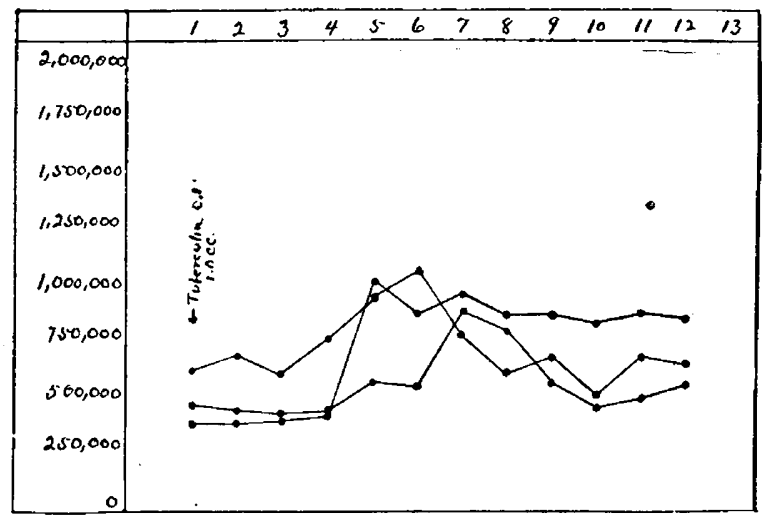

Chart 13.-Effect on the platelet count of 1 c.c. of Koch's old tuberculin given subcutaneously to three rabbits.

tuberculin, and that for this reason, an irritant effect is the rule, and a toxic effect, the result of an overwhelming dose, is not reached in the average case. In the latter type of disease (reduced counts the rule), the platelet count is believed to be influenced by some powerful irritant to the marrow, such as diphtheria toxin or benzol, so that the irritant dose is exceeded in the average case and a reduced count is the rule. The few cases showing an increased count are probably the milder ones in which the toxic dose is not reached.

\section{ABSTRACT OF DISCUSSION}

Dr. Gerald B. Webb, Colorado Springs, Colo.: Dr. Duke's contribution is most welcome, inasmuch as blood platelets have been too little studied. In one case of miliary tuberculosis, and in one of a rapidly fatal tuberculosis following measles, we found the blood platelet count very low, whereas in almost every other case of tuberculosis both in human beings and in laboratory a $\mathrm{nimals}$, we have found the numbers increased. Nature does not often increase elements without design. Thanks to Metchnikoff, we can now better understand the reason for a leukocytosis. More

careful investigations should discover the reason for the increase, under certain conditions, of blood platelets. From our own experiments we have found that (1) blood platelets either contain or supply opsonin; (2) blood platelets are increased at a high altitude; (3) blood platelets can be increased by an artificial hyperemia of the marrow of long bones; (4) blood platelets are increased in carbon monoxid poisoning; (5) blood platelets appear to be increased in the early stages of measles; (6) blood platelets added to a minimum lethal dose of virulent tubercle bacilli do not constantly prevent infection.

Dr. S. H. Hurwitz, San Francisco: For a number of years investigators have been interested in the relationship existing between the formed elements of the blood and the factors of coagulation. Ever since the platelets were first recognized as distinct morphologic entities and not as disintegration products of leukocytes, the relationship of these elements to hemorrhagic diseases became a subject for investigation. Until recent years, however, we did not have methods available for studying the factors of coagulation and it was therefore difficult to find out what the relation of the formed elements of the blood to these factors was. At the present such studies have been made possible by the methods given us by Dr. Howell of Baltimore.

Stimulated by the observations on a patient with bleeding from the gums and purpura, with anemia and considerable reduction in the platelets, associated with a diminution in the circulating prothrombin, we attempted to reproduce this condition experimentally. Like Dr. Selling, we were able to produce by benzol injections in rabbits a picture of aplastic anemia with marked destruction of the marrow and a reduction in the formed elements, especially the leukocytes and blood plates. In some instances the blood platelets were reduced to 30,000 and associated with this drop there occurred a reduction in the circulating prothrombin. This observation is in harmony with the proof that blood platelets contain prothrombin, although it is unlikely that they are the only source of this factor. We were also able to follow the antithrombin and fibrinogen in these same animals. These two factors have been found to fluctuate little from the normal.

Dr. W. W. Duke, Kansas City, Mo.: The platelets surely must perform some very active function in the body, varying in number as they do under so many conditions. The observation of Dr. Webb that platelets contain opsonin is interesting indeed, and it would not be surprising if it were discovered that platelets play an active rôle in immunity. The observation of Dr. Hurwitz that blood in which the platelet count is reduced, contains less prothrombin than normal blood, is in line with what we might expect from the work of Morowitz and Bayne-Jones showing that platelets contain prothrombin. With these facts known, it is a little surprising to find that blood which is nearly free from platelets may clot with great rapidity. In a number of patients with purpura hemorrhagica and also in an animal

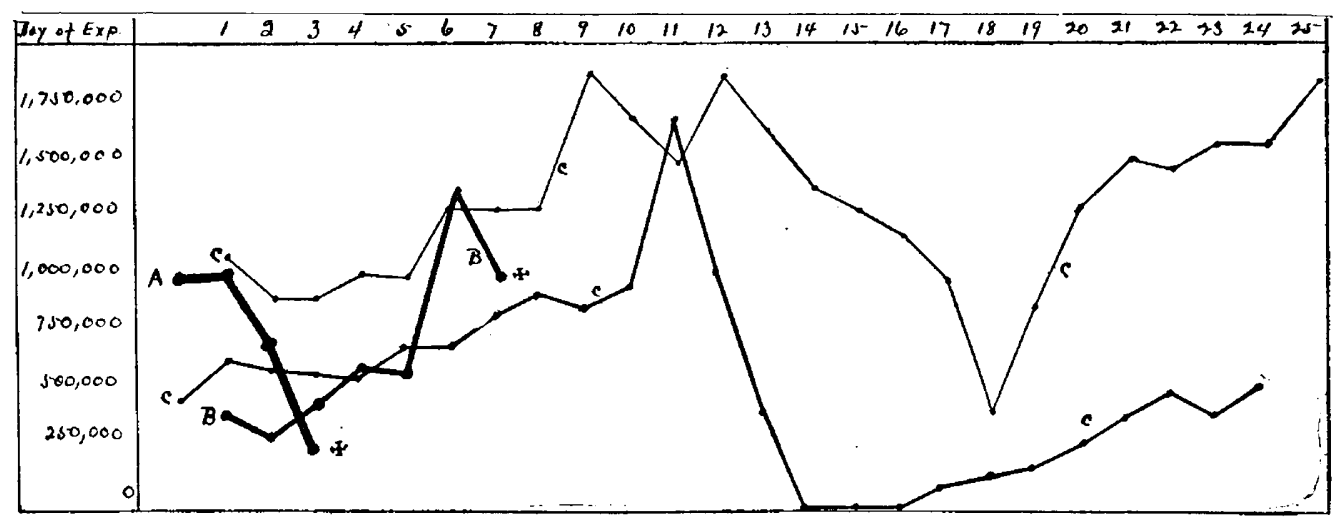

Chart 14.-Effect of diphtheria toxin in varying dosage on the platelet count in rabbits: $(A)$ rapidly fatal dose; $(B)$ smaller, but fatal dose; $(C)$ sublethal doses.

with purpura hemorrhagica produced with diphtheria toxin, the platelet count varied from 10,000 to less than 1,000 . The coagulation time of blood obtained from the ear was invariably normal. Platelets, without question, play an important rôle in stopping hemorrhage. It seems probable that they accomplish this through the rôle they play in the formation of thrombi. Platelets possess a property of rapidly adhering in masses to the wall of a blood vessel at points where the intima is injured, and these masses apparently 
form a nidus for the attachment of fibrin and the laying down of a thrombus. They do this, perhaps, by liberating their thrombin just at the point where it is most useful. Both platelets and fibrinogen seem necessary for the formation of thrombi, for if either is reduced nearly to a point of absence, bleeding from cuts is prolonged.

Dr. Webb's observation that the number of platelets may be increased by passive hyperemia is interesting and important. Dr. McKinley and $I$ have tried this out in tuberculous patients at Dr. Webb's suggestion, and find as he did that the count can often be increased for a number of days in this way. It offers a very simple means for increasing the platelet count artificially. The Roentgen ray may be used in animals either for increasing or reducing the count. It is possibie that some therapeutic application for this may be found.

\section{THE INTESTINAL TRACT *}

\section{S. J. MIXTER, M.D. BOSTON}

Man's interest in the intestinal tract begins at birth and ends only with death. Through its long and tortuous canal pass the foods that supply the body, and here in its laboratory are carried on those complicated chemical and mechanical processes that allow these foods to be fitted for the use of the animal machine, and finally eject the unused portions. Anything interfering with any of these functions is a cause of discomfort, and even of death itself. Is it not natural, therefore, that those having the physical well-being of man in their care, should, from the earliest times, have sought to remedy bodily ills by medication applied to, or through, this channel, confidently hoping that all human disorders might thereby be cured. This hope and even belief still exists, filling the purse of the quack and "patent medicine" manufacturer, who today largely occupies the place of the sorcerer and medicine man of savage tribes.

Medication of some sort, then, was the only method for years, so far as we know, of treating the digestive tract. There were bold and not unskilful surgeons in the older civilizations, as witness the formidable operations on the skull and perhaps the brain, shown by the great number and variety of trephinings done with instruments of stone, found in Peru and elsewhere. These mummies and their bones have handed down their story through the centuries, and in them we can recognize the operative successes and failures as plainly as though these men were alive today, or perhaps on the necropsy table.

There is no such record, however, of operations on the intestinal tract; per haps they were performed, but even in the mummy we find nothing to suggest it, though in the mummy have been found evidences of appendicitis. It is possible that in the prehistoric as well as in later days, torn or cut intestines protruding from a wound may have been sewed up and the patient cured.

The surgeon first operated on the beginning and the end of the intestinal tract, operations on the esophagus and rectum being done at a comparatively early date, but the peritoneal cavity was supposed to be such a dangerous region that few invaded it.

The real beginning of intestinal surgery was not more than fifty years ago, and step by step it has advanced until today there is not an inch of the

* Read before the Section on Surgery, General and Abdominal, at the Sixty-Sixth Annual Session of the American Medical Association, San Irancisco, June, 1915. canal or any of its appendages that has not been attacked. It may be well to briefly mention here some of the things that have already been accomplished.

Beginning with the esophagus, we find that the congenital or acquired malformations, like pouch, may be cured, sometimes by excision, sometimes without, strictures dilated, and malignant growths at least exposed to the view of the surgeon. Excision of such growths, however, is still in the early experimental stage and should not be attempted by the general surgeon. There is no organ more difficult to reach or more dangerous to operate on than the esophagus in the thorax. Some day, let us hope in the not distant future, excision of esophageal growths will be one of the recognized surgical procedures.

Certain surgeons who have had large experience in thoracic work, experienced in the technic of differential pressure, either by the use of the cabinet, or with intratracheal anesthesia, are working and experimenting in this field, and excision of the esophagus, in man, should be left in their hands for the presentenough has already been accomplished to show the probability of future success.

The stomach is certainly a most tolerant organ. For years it is generally either starved or overfed. It must receive and take care of all kinds of substances from milk to clay. It is tanned with tea, irritated by alcohol, tortured by drugs, alternately scalded and chilled, and yet it works on, doing its best though receiving the blame which should fall on its owner or the other organs. Some people complain of their "bad stomachs" all their lives, while in reality the poor thing is not at fault and is doing its best. Its great failing is that it is too sympathetic, reflecting the troubles of its neighbors.

It is also abused surgically without showing resentment. Being by nature a cleanly organ and not infested with the dangerous fauna and flora of the lower intestine, it is operated on with comparative impunity. Were this not true, the daily mortality from operative procedures, some good, some indifferent and many bad, would be enormous. It is cut into and cut out, it is stitched into faulty positions, puckered and drained, properly or improperly, but still the patient survives. Formerly, the would-be surgeon, just out of the medical school, began his operative experiments by amputating a breast, one of the most difficult of operations, by the way, if properly done, but now he is not satisfied until he has done something to a stomach.

In 1881 it was my great privilege to see Billroth do the first successful resection of the pylorus-that was really the beginning of gastric surgery as we know it today. Step by step it has advanced, until now there are few more brilliant results to be obtained by the skilful and judicious operator than in this field. Men are saved from years of suffering, invalidism and death itself by the surgeon who knows his business.

The question of the treatment of malignant disease of the stomach has been pretty thoroughly settled in the surgical mind, radical excision in early cases giving a fair percentage of cure with slight operative mortality. Excision of chronic ulcers is an accepted fact, and operations for pyloric stenosis, whether by the Finney operation or by gastro-enterostomy, give brilliant results. Duodenal ulcer has become a surgical disease in a great measure, the only question in the 